\title{
Enhancing the energy efficiency of domestic dryer by drying process optimization
}

DOI:

10.1080/07373937.2017.1356329

\section{Document Version}

Accepted author manuscript

Link to publication record in Manchester Research Explorer

\section{Citation for published version (APA):}

Wei, Y., Gong, R., Ning, L., \& Ding, X. (2017). Enhancing the energy efficiency of domestic dryer by drying process optimization. Drying Technology. https://doi.org/10.1080/07373937.2017.1356329

\section{Published in:}

Drying Technology

\section{Citing this paper}

Please note that where the full-text provided on Manchester Research Explorer is the Author Accepted Manuscript or Proof version this may differ from the final Published version. If citing, it is advised that you check and use the publisher's definitive version.

\section{General rights}

Copyright and moral rights for the publications made accessible in the Research Explorer are retained by the authors and/or other copyright owners and it is a condition of accessing publications that users recognise and abide by the legal requirements associated with these rights.

\section{Takedown policy}

If you believe that this document breaches copyright please refer to the University of Manchester's Takedown Procedures [http://man.ac.uk/04Y6Bo] or contact uml.scholarlycommunications@manchester.ac.uk providing relevant details, so we can investigate your claim.

\section{OPEN ACCESS}




\section{Enhancing the Energy Efficiency of Domestic Dryer by Drying Process Optimization}

\section{Yuhui Wei, R. Hugh Gong, Lin Ning \& Xuemei Ding}

To cite this article: Yuhui Wei, R. Hugh Gong, Lin Ning \& Xuemei Ding (2017): Enhancing the Energy Efficiency of Domestic Dryer by Drying Process Optimization, Drying Technology, DOI: 10.1080/07373937.2017.1356329

To link to this article: http://dx.doi.org/10.1080/07373937.2017.1356329

Accepted author version posted online: 19 Jul 2017.

Submit your article to this journal $\sqsubset$

Џ Article views: 1

Q View related articles $\asymp$

View Crossmark data $\asymp$ 


\title{
Enhancing the energy efficiency of domestic dryer by drying process optimization
}

\author{
Yuhui Wei
}

College of Fashion and Design, Donghua University, Shanghai, P.R. China

Textiles, School of Materials, University of Manchester, Manchester, UK

Key Laboratory of Clothing Design \& Technology, Donghua University, Shanghai, China

\author{
R. Hugh Gong
}

Textiles, School of Materials, University of Manchester, Manchester, UK

Lin Ning

College of Fashion and Design, Donghua University, Shanghai, P.R. China

Key Laboratory of Clothing Design \& Technology, Donghua University, Shanghai, China

$$
\text { Xuemei Ding }
$$

College of Fashion and Design, Donghua University, Shanghai, P.R. China

Key Laboratory of Clothing Design \& Technology, Donghua University, Shanghai, China 
Address correspondence to Xuemei Ding, Tele: + 86 15821882692. Fax: + 8602162193067.
E-mail: fddingxm@dhu.edu.cn

\begin{abstract}
The domestic tumble dryers are becoming indispensable household appliances and responsible for up to $10 \%$ of the total residential energy use in developed countries. However, their energy efficiency is low. In this paper, the development of a multi-sensor computer-controlled prototype platform for fabric drying is described for improving the efficiency of dryers. The prototype platform enables the real-time control and recording of key drying parameters including heater power, air flow velocity, rotating speed of drying drum and drying cycle time. These parameters are automatically adjusted according to the exhaust air humidity instead of the temperature which is used traditionally. Additionally, a new drying model of dividing the drying process into 4 stages based on the humidity of the exhaust air has been investigated in order to further increase the energy saving. The performance of this staged drying model is experimentally evaluated in respect to energy consumption, drying time, and the smoothness of fabric after drying. The results clearly indicate that the staged controlling of heating power input not only decreases energy consumption by $21.5 \%$ but also improves the fabric smoothness by 0.9 grade compared to using a single heating power input for the whole drying process. The research outcome can enable the design and production of new dryers that are more energy efficient and lead to dried clothes that require less ironing, which in turn further reduces energy consumption.
\end{abstract}

KEYWORDS: drying efficiency, drying, experiment validation, fabrics, platform

\title{
Introduction
}


The use of tumble dryers is increasing continuously because of their convenience. They are space efficient and independent of weather conditions. ${ }^{[1]}{ }^{[2]}$ However, fabric drying is an energy-intensive operation. ${ }^{[1]},{ }^{[3]}{ }^{[4]}$ Domestic clothes dryers are responsible for up to $10 \%$ of the total residential energy consumption in developed countries. ${ }^{[5]}$ Current dryers are also very inefficient, nearly $60 \%$ of the total energy consumed by currently available dryers is wasted. ${ }^{[6]}{ }^{[7]}$ As consumers are becoming more and more aware of the environmental impact of energy consumption and energy costs are increasing, energy consumption of domestic dryer is playing a more and more important role when consumers make purchase decisions. Improving drying-efficiency is also a primary concern for dryer manufacturers. ${ }^{[8]}$

Significant amount of research has been reported in the literature on improving the energy efficiency of dryers. ${ }^{[9-11]}$ Stawreberg pointed out that the drying efficiency of drying small loads can be significantly improved by using the control strategy of specific mathematical model. ${ }^{[2]} \mathrm{Ng}$ and Deng developed an energy saving method based on the use of the equilibrium moisture content in ambient environment as a termination point. ${ }^{[1]}$ Van Meel reported the use of air recirculation to improve the adiabatic convection batch drying rate. ${ }^{[12]}$ Fudholi et al. showed that controlling the temperature and humidity of drying air could reduce energy use. ${ }^{[13]}$ Piccagli et al. reduced the drying energy consumption by a using PID controller to optimize the heater temperature. ${ }^{[14]}$ Conde improved the energy efficiency by using heat exchangers for energy recovery instead of air recirculation. ${ }^{[15]} \mathrm{Wu}$ et al. indicated that inlet conditions considerably 
affected drying efficiency and drying system performance. ${ }^{[16]}$ Ameen and Bari reduced energy consumption of drying by using the waste heat of the condenser in a domestic air conditioner. ${ }^{[17]}$ Deans reported that $16 \%$ of the input energy was saved by exploiting the energy of exhaust air. ${ }^{[7]}$ Krokida and Bisharat found that drying efficiency of tumble-dryers could reach $79 \%$ by simultaneously using heat pump and heat exchanger. ${ }^{[18]}$

The reported research is mainly devoted to introducing new technologies such as additional recirculation system of exhaust air and microwave heating, and optimization of drying parameters to achieve better drying efficiency, but in all these studies, the drying process is considered as a single drying stage. However, the moisture removal rate of fabric, the surface temperature and instantaneous moisture content of fabric, the temperature and humidity of drying air are all continuously changing during the drying process. ${ }^{[19]},{ }^{[20]}$ Using the same parameter settings for the entire drying process severely limits the scope of drying process optimization. Further, as the main objective of drying is to remove moisture from the drying load, using the humidity of the exhaust air as a control parameter is more direct and logical than using time or temperature as reported in the literature.

In addition, some scholars have reported the impact of household washing parameters (water temperature, washing time, agitation of the drum and so on) on the appearance of cotton fabric, but there is little information about the impact of drying parameters on appearance of fabric (wrinkling), its forming mechanism and forming stage during tumble drying in the 
scientific literature. ${ }^{[16]}{ }^{[21-23]}$ Since fabric is the object served by dryers, the appearance of fabric after drying should be considered as well as energy consumption. ${ }^{[24]}$ Therefore, it is reasonable to adjust key drying parameters by stages based on the drying characteristics in each stage, and then achieve the purposes of better appearance of drying loads and understanding of woven cotton fabric wrinkling mechanism during domestic tumble drying.

Moreover, our approach of dividing the drying process into several stages according to the exhaust air moisture content and optimizing the drying process accordingly is novel and can potentially lead to more energy efficient dryer designs. In addition to energy efficiency, the importance of fabric smoothness is also considered for the first time in drying process optimization.

\section{Background}

\section{Current state of domestic dryer}

The dryers currently on the market suffer from problems including low energy efficiency, non-uniformity of drying, long drying time and poor clothes appearance after drying. The most commonly used termination control strategy is based on the air temperature in the drum. ${ }^{[1]}$ This strategy is easily influenced by ambient temperature and dry load. Also, the temperature detected does not reflect the actual temperature of the clothes. This termination control strategy can thus lead to over-drying and energy waste. In addition, current dryers do not continuously monitor the drying process and adjust the drying parameters such as the air flow velocity and rotating speed 
of drying drum. These key parameters which affect the drying efficiency are fixed. Over-drying can also be caused by the lag and inaccuracy in the current temperature termination control strategy. In order to overcome drying non-uniformity caused by the uneven distribution of heat and to achieve the drying degree of clothes specified by the relevant standards, the current solution is to extend the drying time and increase the drying power. These lead to not only increased energy consumption and drying time, but also more creased clothes and even damaged clothes.

\section{Strategy for reducing dryer energy consumption and improving dryer}

\section{performance}

In general, energy-saving methods for dryers fall into two main categories: reducing the evaporation load (e.g., reducing initial moisture content, avoiding over drying); and increasing the drying efficiency (e.g., optimizing operating parameters, reducing heat loss, improving the efficiency of heat recovery). In order to optimize the operating parameters and avoid over drying, it is necessary to monitor and analyze the drying process, and then understand the moisture migration mechanism of fabric drying in dryer.

A typical drying process is shown in Figure 1. By observing the changes of the moisture content of fabric and humidity of exhaust air during the drying process (Figure 1a), we can find that the fabric drying process may be divided into four different drying stages. In stage 1 , the fabric moisture content changes very slowly while the $\mathrm{RH}$ of exhaust air rises rapidly. The 
temperature of fabric is below the temperature of drying air. Sufficient temperature is a prerequisite for evaporation of water under normal atmospheric pressure conditions. ${ }^{[4]}$ In this stage, energy is mainly used for heating the fabric by conduction and convection instead of evaporation of water, and the moisture content of fabric remains almost constant. During this stage, the migration of moisture mainly depends on the mechanical rotation of the drum instead of convection, and thus migrated moisture is free moisture attached mechanically on the fabric surface and yarns surface. To reduce drying time, we should aim for the exhaust air to reach maximum humidity at the fastest speed. The fabric moisture content then starts to fall rapidly, signaling the start of stage 2 . The corresponding $\mathrm{RH}$ of exhaust air is around $95 \%$. During stage 2, the RH of the exhaust air remains close of saturation level. The moisture content of the fabric remains high and the surface of the fabric is completely covered with moisture. During this stage, the migrated moisture is mainly free moisture which the moisture on the fabric surface and pores between yarns. This kind of moisture is very easy to evaporate because of weak binding force between this moisture and fabric. The temperature of the fabric is almost equal to wet bulb temperature of drying air. Hence, in this stage, energy provided by heater power is mainly used for evaporation of water, and the moisture content of fabric decreases rapidly through capillary flow of free moisture inside the voids. As drying proceeds, migration of moisture within the fabric cannot compensate for the evaporation of free water on fabric surface, and the free moisture inside fabric gradually declines to the critical moisture content. ${ }^{[21]}$ Subsequently, the drying rate decreases and this indicates the start of stage 3. In our case, the critical moisture 
content of fabric decreased from around $55 \%$ to around $17 \%$. The corresponding exhaust air RH decreased from around $95 \%$ to around $42 \%$. In this stage, the moisture content of fabric is mainly free moisture (moisture retains in pores between fibers) and the bonding force of fabric and free moisture (moisture retains in pores between fibers) is larger than that of free moisture (moisture retains in pores between yarns and surface moisture on fabric). The temperature of the fabric rises towards the wet bulb temperature of the air and the humidity of exhaust air decreases rapidly. According to thermodynamics, increasing the fabric surface temperature is not conducive to the evaporation of water due to the vapor pressure on fabric surface being greater than that inside the fabric. Most of the energy provided by the heater is used for increasing the fabric temperature instead of the evaporation of water. Hence, in this stage, a lower heater power can be employed to reduce energy consumption.

When the fabric surface moisture content reaches its lowest level, the drying process should end in principle. However, due to the uneven moisture distribution, the drying process usually continues for a short while to make sure the fabric is dried thoroughly. This extended drying is stage 4 during which the fabric surface temperature rises rapidly and the humidity of exhaust air reaches the minimum. During this stage, migrating moisture is bound moisture (directly absorbed on fibers) which it is very difficult to remove because of greater binding force of this kind of moisture and fibers. 
From the previous analysis, we can conclude that the removal rate of moisture is $\underline{\text { simultaneously influenced by several factors such as the moisture content of fabric, heater }}$ power, air flow rate of the convective medium and the rotating speed of drying drum. Therefore, the above mentioned factors should be considered for the optimization process.

Based on the drying dynamics theory of porous materials, the wet fabric contains three different kinds of moisture including free moisture (or unbound moisture), bound moisture and capillary moisture as shown in Figure 2. ${ }^{[25-27]}$ Free moisture is moisture retained on fabric, yarn and fiber surfaces and moisture in pores between yarns, between the fibers within the yarns and in pores within the fibers. The binding force of free moisture and fabric is relatively small, so free moisture is migrated from fabric in the early drying process (mainly including warming-up stage and constant drying rate stage). While bound moisture (directly absorbed in macromolecular structure and hydrophilic group of fiber) and capillary moisture (within capillary voids inside fibers) is very difficult to remove from fabric due to greater binding force between the two kinds of moisture and the fabric, and since this combination generally involves chemical bond combination and thus removing this kind of moisture requires breaking the chemical bond (hydrophilic groups of cotton fiber and polar groups of the water molecule) between molecules. ${ }^{[26]}$ The two kinds of moisture are generally considered to be difficult to migrate or should not be removed to avoid fabric damage. 
Through the above analysis, it is clear that the moisture removal rate of fabric experiences four different stages. The evaporation mechanisms of moisture and the energy required to evaporate moisture are different during different stages, indicating it is possible to make use of this characteristic of drying process to reduce energy consumption. In other words, the drying process can be optimized to save both drying time and energy consumption, as well as to avoid over-drying by using different drying parameters for different stages and accurately terminating the drying process of dryer.

\section{Design and Implementation of Staged Drying System}

In order to monitor the drying process and accurately control the key parameters of fabric drying such as heater power, air flow velocity, and drum rotating speed and direction, a multi-sensor prototype platform was designed and built in accordance with the block diagram shown in Figure 3. The prototype platform consists of a drying process monitoring system, a data acquisition system and a drying parameter-adjustable control system. A PC computer is used to run the control algorithm in order to maintain the drying parameters at desired set-points. The main parts of the prototype platform are presented in Figure 4.

\section{The monitoring system}

Fabric drying is a simultaneous heat and moisture transfer process of porous media (Figure 5). During the drying process, fabric continuously absorbs heat from the heated air, while moisture in the fabric is also continuously removed to the drying air, and thus, temperature 
and moisture content of fabric, temperature and humidity of air are all variable in the drying process. ${ }^{[21],[28]}$ Monitoring key process parameters during fabric drying are important to understanding the heat and moisture transfer mechanism of the drying process.

In order to achieve the above objectives, eight K-type thermocouples (PT100) with accuracy of $\pm 0.1^{\circ} \mathrm{C}$, temperature and relative humidity sensors (FTS64-2011-MD with an accuracy of $\pm 0.5^{\circ} \mathrm{C}$ for temperature, $\pm 3.0 \%$ for humidity, Eyc, Masuda Technology Co., Ltd, Taiwan), an air flow velocity senor (THS74-A11-1800-M with an accuracy of $\pm 0.33 \mathrm{~mm} / \mathrm{s}$, Eyc, Taiwan), a Huoer sensor (A1103LWA-T with an accuracy of $\pm 2 \mathrm{rpm}$, Shanghai Kexin Electronics Co., Ltd., China), and an infrared thermal camera (OPI-450, Germany) were installed at appropriate positions in the dryer as shown in Figure 3 and Figure 4. Data of fabric drying process was transmitted in real time by using JY-DAM-PT12 and JY-DAM1012 data acquisition card (Juying Technology Co., Ltd. Beijing, China). PID neural network control algorithm was used for the real-time data control. Matlab simulation software was used to simulate the drying system. The drying efficiency is calculated in real-time.

\section{Monitoring parameters}

Temperature and humidity of drying air

In order to monitor the temperature and humidity of various sections of the dryer, corresponding sensors are used as shown in Figure 3 and Figure 4. Dryer heater power is no more than $4000 \mathrm{~W}$ in general and it can heat air to $180^{\circ} \mathrm{C}$. Most available temperature and 
relative humidity sensors have operating range below $100^{\circ} \mathrm{C}$ and are not suitable for our condition. Hence, eight PT100 are used as described below. Three K-type thermocouples (PT100) with accuracy of $\pm 0.1^{\circ} \mathrm{C}$ and temperature range $0-200^{\circ} \mathrm{C}(\mathrm{T} 2, \mathrm{~T} 3, \mathrm{~T} 4)$ are fitted around the heater to obtain an average temperature of the heated air. The other five K-type thermocouples are placed close to the lint trap (T5), inlet of the exhaust duct (T6), ambient temperature in control box (T7), outlet of the exhaust fan (T8) and downstream of the heater, namely inlet air of the dryer (T1), respectively. In order to measure the humidity of air inside the drying chamber, several temperature and relative humidity sensors (FTS64-2011-MD with a accuracy $\pm 0.4 \%$ for temperature scale $0-100^{\circ} \mathrm{C}$ and $\pm 2 \%$ for relative humidity in the interval 0-90\%, Eyc, Masuda Technology Co., Ltd, Taiwan) are fitted at the dryer door (T/RH1). Relative humidity (RH) of exhaust air is measured and recorded using a temperature and relative humidity sensor (Eyc,TH34-A11-1500-MP with a accuracy $\pm 0.4 \%$ for temperature scale $0-60^{\circ} \mathrm{C}$ and $\pm 2 \%$ for relative humidity in the range of $0-90 \%$ ) at the exit of the exhaust duct (T/RH2).

The data of temperature and humidity are recorded using a data logger (JY-DAM-PT12, Juying Technology Co., Ltd. Beijing, China) and transferred to the PC every $2 \mathrm{~s}$.

\section{Temperature and moisture content of fabric}

In the testing process, to obtain more information about drying fabric data such as weight and temperature, an infrared camera with digital transmitter (OPI-450, Germany) and an electronic scale (Global Weighing Technologies, TCS-XC-A with $\pm 5 \mathrm{~g}$ accuracy, Shanghai, 
China) are utilized. The weight of the fabric can be measured continuously during the drying process at pre-determined time intervals by the scale under the dryer. The data is transmitted to the same computer though 232 communication protocols every $2 \mathrm{~s}$. The data are used to analyze the heat and mass transfer mechanisms during fabric drying.

\section{Control system}

The drying efficiency of dryers is simultaneously influenced by several factors such as the moisture content of fabric, heater power, air flow velocity and rotating speed of drying drum, etc. ${ }^{[21]}$ Some external control devices such as a digital voltage regulator, DC motor and an external fan are employed to achieve the purpose of continuously adjusting and controlling the parameters affecting fabric drying. The control principle of the prototype platform is shown in Figure 6. The measurements of heater power, air flow velocity and rotating speed of drying drum serve as feed forward signals to adjust the corresponding control regulators. Additionally, Relative Humidity of the exhaust air serves as feed forward signal to identify the drying stage and terminate the drying process. The control system can accurately and rapidly detect the drying degree of fabric to avoid over-drying or under-drying. In this way, the final moisture content of fabric is maintained within specifications. In contrast, conventional dryers treat the whole drying process as a single stage and reply on temperature to control the drying process.

\section{Adjustable Parameters}

\section{Electric heating element}


The main heat source of the dryer is an electric heating element. To obtain an optimum heating model for the dryer, it is very important to assess the dryer efficiency under different heating conditions. However, existing dryers on the market have fixed heater power. For our drying platform, an electric heating element of $4 \mathrm{KW}$ and a digital voltage regulator are utilized for adjusting the heater power according to the drying conditions as shown in Figure $\mathbf{3}$ and Figure 4. The heater power is controlled by the digital voltage regulator connected to the power line of the heater. The heater power is calibrated by an electric power meter.

\section{Rotating speed and direction of drying drum}

The rotating speed of the drum affects the fabric motion in the drying chamber and the degree of fabric spread, and subsequently affects the area and time of heat exchange. It significantly affects the removal rate of water in fabric. ${ }^{[29]}$ The drum in most dryers is driven by an AC motor which cannot change direction or adjust the rotating speed. In our system, a DC motor is used for driving the drum as shown in Figure 3 and Figure 4. The DC motor is controlled by a PLC unit which is programmed to start and stop the drum, and adjust the rotating speed of drying drum.

\section{Air flow velocity}

Domestic dryers on the market are equipped with a wind impeller in the duct to achieve air flow in the drying system. The air flow velocity is determined by the design and size of the impeller. The air flow velocity in the dryer cannot be controlled due to the fixed impeller. 
However, air flow velocity is the most critical factor affecting the drying air movement, and it directly impacts on the heat and mass exchange between the drying air and fabric. To explore the impact of different air parameters including the air temperature, humidity and volume on the dryer efficiency and overall performance, an external fan and a digital voltage regulator are used for controlling the air flow velocity as shown in Figure 3 and Figure 4. The air flow velocity can vary from $00 \mathrm{~mm} / \mathrm{s}$ to $199 \mathrm{~mm} / \mathrm{s}$ and the power consumption is approximately $270 \mathrm{~W}$. The air flow velocity is controlled by the digital voltage regulator connected to the power line of the external fan. The air flow velocity is calibrated by an air flow sensor. The air flow sensor for real-time measurement is positioned in the mid-section of the wind tunnel outlet (AV) as shown in Figure 3.

\section{Parameter Adjustment Method}

As can be seen from the above analysis, fabric drying consists of several successive periods that each period has own different drying characteristics. ${ }^{[30]}$ Adjustment drying parameters using simple on-off controllers or manual switching is therefore insufficient if energy (electricity) consumption is concerned. In contrast, it is particularly effective approach to build-in long-horizon feedback system for fabric drying by tracing drying parameters to maintain higher efficiency during the whole drying process. Hence, we developed a drying platform that enables the control of heater power, air flow velocity, rotating speed of drying drum and maximum air temperature in the drying chamber during the drying process. At the beginning of 
the process, heater power, air flow velocity, rotating speed of drying drum and maximum air temperature in drying chamber are set according to our design of experiment (DOE). Additionally, the strategy for regulating drying platform's behavior is feedback control, throughout which the drying conditions are effectively adjusted according to our pre-set points. The operation flow chart is shown in Figure 6. As shown that the control system changes position of the valve (adjust operational conditions) according to the process phase and keeps measured drying parameters close the respective set-point. Specifically, the first step is to set the parameters based on the experimental requirements. This step gives some signals (the desired set points) to the drying platform. The second step is to determine the status of the drying process by comparing the control parameters with their set points, in which software system of drying platform compared the controlled variables (such as heater power, air flow velocity and rotating speed of drying drum) with the above desired set points. The difference signal, suitably processed by the controller, is then used to modulate the input parameter being used as the control variable. The digital voltage regulator, speed controller and relay are switched on when these parameters are not equal to the set points. The third step is to determine the drying stage based on the measurement of exhaust air humidity during the drying process and automatically adjust the drying parameters or terminate the process by comparing the exhaust air humidity with set cut-off points. In this step, the software of drying platform also launches the data acquisition system to track the temperature and humidity of each location during the drying process, and thus achieving the purpose of sharing some common characteristics with learning systems and 
provide a reference for future parameters setting. The above three steps are repeated until the desired drying degree of fabric is achieved.

\section{Data Acquisition System}

\section{Data transmission}

The data transmission system consists of a PC, data acquisition boards, and various sensors. The data transmission path is divided into two steps:

All sensor signals of the drying platform are filtered and digitized by using related signal processing methods. And then using RS232 as a communication protocol, send all sensor signals transmitted to PC.

\section{User interface}

In order to facilitate user operations, a simple user interface was designed. Figure 7 shows a screen shot of the user interface. Drying parameters including the heater power, air flow velocity, rotating speed of drying drum and maximum air temperature in chamber base are set through this interface. Various process variables can be real-time observed and recorded by this system interface. These include temperature, humidity and flow velocity of air, rotating speed of drying drum, surface temperature and weight of fabric. The acquired experimental data is used for the calculation and analysis of dryer efficiency. The data acquired from all the sensors can be 
plotted on screen at the top left corner of the interface. A photograph of the prototype platform is shown in Figure 8.

\section{Experiment evaluation for drying process optimization}

The drying platform can be used to explore the effects of parameters including heater power, air flow velocity and rotating speed of drying drum on the dryer efficiency and clothes smoothness, and to develop mathematical models for the drying process. In this paper, we focus on the important issue of energy efficiency.

\section{Experimental steps}

(1) The drying experiments were carried out in a laboratory where room temperature and relative humidity were in the range of $23 \pm 2^{\circ} \mathrm{C}$ and $\mathrm{RH} 68 \pm 10 \%$, respectively.

(2) The prewashed cotton fabric was cut into $38 \times 38 \mathrm{~cm}$ and dried under constant temperature and humidity (temperature: $20^{\circ} \mathrm{C} \pm 2^{\circ} \mathrm{C}$, humidity: $65 \% \pm 2 \%$ ). The detailed properties of the prewashed fabrics are listed in Table $\mathbf{1 .}$

(3) The samples were prepared by soaking in tap water for 15 minutes in a washing machine followed by a spin cycle of 5minutes with a speed of 1000rpm to obtain the initial moisture content of fabric $70.0 \% \pm 5 \%$.

(4) The heater power, air flow velocity and rotating speed of drying drum were set as shown in Table 3. 
(5) The energy consumption and drying time were recorded when the drying process was completed.

(6) In order to assess the effect of staged drying model on smoothness appearance, three trained observers graded the fabrics independently according to "AATCC Test Method 124- Smoothness Appearance of Fabrics after Repeated Home Laundering". ${ }^{[37]}$ This test method is designed to evaluate the smoothness appearance of flat fabrics after repeated home laundering including domestic tumble dry. Rating values between on and five are given, and a high rating value represents less wrinkling on the specimen. In this study, average smoothness ratings were rounded to the closest on decimal point. And all drying experiments were repeated at least three times.

(7) In order to calculate the final moisture content of fabric the original weight and weight at the end of the drying were weighed by a scale (Christ, Germany) with an accuracy of $0.1 \mathrm{~g}$. In every experiment, weight of fabric was measured at least twice. The final moisture content of fabric was calculated using Equation (1).

$$
\mathrm{w} \%=\frac{W_{i}-W_{o}}{W_{o}} \times 100 \%
$$

Where $\mathrm{w} \%$ is the final moisture content of fabric; $\mathrm{W}_{\mathrm{o}}$ is initial weight $(\mathrm{g})$ after conditioned for 24 hours at $20^{\circ} \mathrm{C} \pm 2{ }^{\circ} \mathrm{C}, \mathrm{RH} 65 \% \pm 2 \%$; $\mathrm{W}_{\mathrm{i}}$ is weight of fabric $(\mathrm{g})$ when drying process ends.

\section{Experimental details}


To evaluate the developed platform, we compared the staged drying model with a commercial dryer with a fixed drying model. The experimental procedures were obtained based on the above analysis. The details of the $\mathrm{RH}$ of exhaust air for the division of the drying stages are determined based on the analyze of the changing law of temperature and relative humidity of the outlet air (previous experimental test: different heater power), machine limits, the previous literature review, the recommendation of dryer technicians, combined with the multi-objective optimization method -- MOPSO (Particle Swarm Optimization) with the targets of minimum energy consumption. The details are shown in Table 2. The drying conditions for each stage were optimized by using multi-objective optimization methods MOPSO (Particle Swarm Optimization) with the targets of minimum energy consumption. Table 3 shows the drying parameters. Each experiment was repeated 3 times and the average results are shown in Table 4. The fabric appearances following the two drying models, single-process and staged-process, are shown in Figure 9.

\section{Results and Discussion}

Table 4 and Figure 9 present the effect of the staged drying model on drying performance in respect to energy consumption, drying time, final moisture content of fabric and fabric smoothness. From Table 4, it is clear that, except Test No. 6, staged-process drying is always more efficient in energy consumption compared with single-process drying (Test No. 1). And Test No. 2 shows the lowest energy consumption with an energy consumption reduction of 
about $21.5 \%$ compared with single process drying. In addition, it is worth mentioning that the following discussion is for comparison results of Test No. 2 (the optimum staged drying procedure in this study) and the common single drying procedure of dryer (Test No.1).

In the first drying stage, the moisture content of fabric remains almost constant (as discussed in Figure 1) because of the temperature of fabric being below that of the drying air, thus it needs high levels of heater power to be heated up to reduce fabric-heated time. Therefore, a higher heater power $(4000 \mathrm{~W})$, lower air flow velocity $(6.88 \mathrm{~mm} / \mathrm{s})$ and higher rotating speed of drying drum (50-55rpm) should be used (Table 4). Higher heater power (4000W ) provides more energy and increases the fabric temperature more quickly. Lower air flow velocity $(6.88 \mathrm{~mm} / \mathrm{s})$ keeps the air in the drying chamber longer which helps the energy transfer to the fabric. Higher rotating speed of drying drum $(50-55 \mathrm{rpm})$ helps to spread the wet fabric and improves energy transfer to the fabric.

In the second drying stage, large amounts of free moisture (retained on fabric surface and pores between yarns and pores between fibers) will be removed and require more energy. Additionally, the moisture remove rate for this stage is also fastest as compared to other stages of the drying process. This is because free moisture (retained on fabric surface and pores between yarns and pores between fibers) is mechanically connected to the fabric. ${ }^{[31]}{ }^{[32]}$ A higher heater power $(4000 \mathrm{~W})$ and a higher air flow rate $(8.5 \mathrm{~m} / \mathrm{s})$ help the evaporation and removal of moisture from the fabric (see Table 4). The drying fabric is easier to spread than the wet fabric, 
so a slower rotating speed of drying drum (45-50rpm ) is needed and this saves energy (Table 4). Also, a slower rotating speed of drying drum (45-50rpm ) allows the fabric to develop a complex movement pattern involving sliding, falling, swinging and rotating. A complex movement pattern improves the drying efficiency compared to a single movement pattern because it increases the contact surface between the fabric and the air. ${ }^{[30]}$

However, in stage 3, the fraction of wet area decreases with decreasing surface moisture content, and free moisture content is also less as compared to free moisture of the constant drying rate stage. ${ }^{[5]}$ And during this stage, temperature of drying air increases sharply and leading to partial pressure of water vapor increases quickly. While partial pressure of moisture inside fabric can't increase proportionally, outside vapor pressure is higher than the internal vapor pressure, and thus hinders the migration of water, so that the removal rate of water decreases. ${ }^{[33]}$ Therefore, during this stage, a lower heater power $(3000 \mathrm{~W})$ can be used to avoid the excessive increase of fabric surface temperature. A high air flow velocity $(8.55 \mathrm{~mm} / \mathrm{s})$ helps the removal of vapor while a low rotating speed of drying drum (40-45rpm) provides the opportunity for the fabric to fully unfold, and thus achieve the purpose of drying air fully contact with wet fabric (Table 4). A high rotating speed of drying drum at this stage will force the fabric to rotate close to the drum wall and decrease the heat and mass transfer area.

In the fourth drying stage, very little moisture is still retained in the fabric and the migration rate is very low. This is because moisture retained the fabric for this stage is mainly 
bound moisture (directly absorbed on chemical bond of fiber) and capillary water (retained in capillary pores of fiber), binding force of this kind of moisture and fabric is relatively large, and thus the migration of this kind of the moisture is more difficult as compared to migrating moisture (free moisture retained on fabric surface and pores between yarns, fibers which is attached mechanically only instead of chemical bond) in early drying stage. Excessive heating power can cause the fabric to over-dry and decrease fabric smoothness or even lead to fabric damage. Therefore, a low heater power $(1500 \mathrm{~W})$, a lower air flow velocity $(6.88 \mathrm{~mm} / \mathrm{s})$ and rotating speed of drying drum (45-50rpm) should be used. Excessive heating power can cause the fabric to over-dry and decrease fabric smoothness or even lead to fabric damage.

Comparing with the single stage drying (Test NO.1), the fabric smoothness of staged drying (Test No.2) improved by 0.9 grade as shown in Figure 9. This is because the staged drying model as a means of reducing swelling stresses in woven yams as wrinkling or buckling become jammed together early in the drying process. In other words, the staged-drying model (Test No.2) delayed the fixing of wrinkles in the woven cloth thereby reducing the level of wrinkling compared with that seen after single-drying (Test No.1).

Additionally, wrinkling is the property that fabric gets a plastic deformation due to rubbing but fails to return to its original dimensions after removing the force or load. And this property depends on external environmental factors including mechanical force and the relative humidity and temperature of air. While drying is to remove moisture from wet fabric by heating 
the air using electrical resistance, indicating that fabric is repeatedly affected by temperature and humidity of drying air in drum. If this influence is strange enough, it is may lead to molecular rearrangements via labile hydrogen bonds. This is because that the heat and absorbed moisture giving a lower energy network between fibers in fabric. And the influence of heat and absorbed moisture leading to reducing energy network gradually increases as the drying process proceeds. This indicated that wrinkling occurs mainly in the later drying process, and thus using lower heater power at latter drying stage (Test No.2) obtained better smoothness of fabric surface as compared to using higher heater power at the latter stage (Test No.1).

Moreover, drying is also a process in which complex mechanical actions are forced onto textiles or clothes, and fabrics are repeatedly spilled by drum to make drying air flow fully contact with the wet fabric and then achieve the purpose of removing moisture from the surface and inner of fabric. It implies that, in domestic tumble dryer, fabrics may undergo complex deformations during tumble drying, including twisting, extension and compression (even though the forces are slight) which leads to the undesirable permanent deformations (wrinkles) occurring. ${ }^{[21]},{ }^{[34]}$ Additionally, agitation during drying would be more crucial to the wrinkling process because agitation is easy to cause unevenness in fabric stress and unevenness of deformation. At this moment, molecular chains fracture and recombine continuously as the tumbling action keeps going on during the drying process. Therefore, adjusting rotating speed of 
drum based on drying stage is useful for the fabric to avoid creases formation. The results of Test

No.2 (staged drying model) and Test No. 1 (single drying model) demonstrates this view.

In addition, based on the fringed-frbril theory, the structure of cotton fiber can be divided into two regions, namely the crystalline region where the molecules are folded together in a regular pattern with a higher degree of lateral order, and amorphous region where molecular chains are tangled together at random. ${ }^{[31]}$ Different regions have different deformation

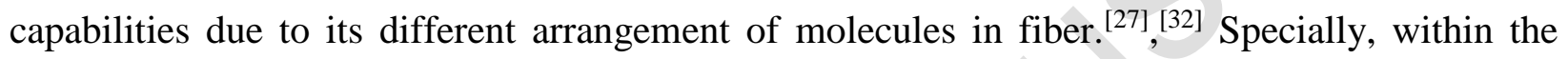
highly ordered regions, polymer chains are aligned contributing to the formation of hydrogen bond, which helps to protect against the force from deformation. Therefore, small and reversible deformation occurs in the crystalline region when forces are placed on the fibers. While in the amorphous region, binding degree of molecular chains remains at low level. When exposed to the external forces, molecular chains slip easily so that hydrogen bonds have high tendency to be broken or newly form in another place. When the applied forces are removed, molecules recover to their original position slowly. If the resistance caused by the dislocation of molecules is greater than the restoring force, permanent deformation will form. The in-homogenous and irreversible deformations turn out to be wrinkles of the fabric. ${ }^{[35]}$ It is recognized that plastic deformation mainly generates in amorphous region. Amorphous region in cotton fiber accounts for approximately $47.1-50.7 \%$ where large amount of hydrophilic groups exists, such as hydroxyl and carboxyl. ${ }^{[27]}$ Once absorbed in the non-crystalline region, moisture molecules bond 
with hydrophilic groups in the form of hydrogen bonds, and then the molecular chains become loose and easy to slip. Drying is a process involving repeated mechanical forces from gravity, centrifugal force and friction. Under these conditions, both fibers and fabrics are more likely to deform when exposed to shear forces or tension/compression stress, even though the forces are slight.

Additionally, the anisotropy in hygroscopic swelling of cellulosic fiber also leads to a certain extent wrinkling. ${ }^{[21]}$ Specifically, after being wetted thoroughly, cross-sectional area of the fiber increases by over $40 \%$, while the length of it only increases about $1 \%$. The uneven recovery is easy to form wrinkle, and the degree of wrinkle formation depend mainly on moisture content of fiber. This indicated that final moisture content of fabric to a certain extent determines the surface roughness of the fabric. Specifically, the lower the final moisture content, the easier it is to wrinkle the fabric. The results of Test No.2 (staged drying model) and Test No. $\underline{1 \text { (single drying model) further demonstrates this view. }}$

And wrinkles of cotton fabric mainly form in the latter part of the whole drying process. This is because large amount of moisture is removed from the fabrics as drying proceeds, indicating that a mass of hydrogen bonds between moisture molecules and hydrophilic groups are replaced by the chemical bonds between cellulose molecules. And the latter is harder to be broken than the former. Then, the wrinkles form and are fixed. Additionally, cotton fibers or fabrics swell when absorbing moisture and then shrink due to moisture loss when drying. ${ }^{[34]}$ Both 
of the two processes are incompletely reversible. Cotton swelling-shrinkage produces a relative displacement between molecules and between molecular chains, resulting in the wrinkles macroscopically. Moreover, amorphous region in cotton fiber accounts for approximately 47.1-50.7\% ${ }^{[27]}{ }^{[34]}$ Molecular chains in amorphous region are easy to slip when applied to external forces especially under high temperature. Near the end of fall-rate drying stage (when the fabric is about to dry), the temperature of the fabric will increase slightly. This increases the motion of molecules and weakens the intermolecular forces. Consequently, cotton fabrics have higher tendency to wrinkle when undergoing large deformation encountered during tumbling in the latter part of the whole drying process. Thus, we can draw a conclusion that wrinkling is associated with higher air temperatures, especially later period of drying process. Using stage drying model is further proven to be reasonable for energy saving.

In addition, the average total drying time by the staged drying procedure is 60 minutes, 5minutes longer than the single stage drying. This is because the energy for removing same quality of water is constant and the drying time is extended due to the lower the heater power. However, the heat and mass transfer efficiency of the staged drying procedures is significantly improved, so that the energy consumption is reduced, when comparing results of Test No. 2 and Test No.1.

When over-drying occurs, negative moisture content of fabric (final moisture content of Test No.1is $-2.17 \%$ ) is possible to appear and appropriate. This is because the initial weight is 
the weight of the fabric fully balanced (cotton fabric absorbs a certain amount of moisture and contains around $7 \%-8 \%$ due to the hygrosopic nature of cotton fibers) under temperature of 20 $\pm 2{ }^{\circ} \mathrm{C}$ and a relative humidity of $65 \pm 2 \%$. While relative humidity of air in drying drum is much below $65 \%$ and the temperature of the air in the dry drum is much higher than $20{ }^{\circ} \mathrm{C}$. This easily leads to lower moisture content in the fabric, thus weight of fabric at the end of the drying is lighter than the initial weight (weight of fabric is conditioned for $24 \mathrm{~h}$ at stander experimental room).

Therefore, we developed the staged drying model (set smaller heater power at the later period of drying compared to the early period of drying) instead of single drying model to avoid inappropriate drying parameters including excess higher heater power, lower final moisture content of fabric (over-drying) at the later period of drying, and so on, and thus improve $\underline{\text { smoothness grade of fabric surface and reduce fabric damage. }}$

\section{Conclusions}

We developed a new prototype platform for fabric drying. The new platform enables the monitor and control of several important parameters such as heater power, drum rotating speed and air flow velocity during the drying process. Following in-depth analysis of the drying process, a new drying model of dividing the drying process into 4 stages based on the humidity of the exhaust air has been proposed and evaluated. The results have demonstrated that the new staged-process drying model has significant potential for energy saving. Compared with the 
single-process drying model, the staged-process drying model not only saved $21.5 \%$ of energy but also improved the fabric smoothness by 0.9 grades. The results can provide a reference for dryer design and performance optimization. Based on the new drying platform, further studies can be carried on the drying process such as on the effect of fabric movement pattern on drying efficiency, drying behavior of different materials (such as cotton, silk, wool, polyester and linen), heat and mass transfer mechanism of drying process, and the fluid dynamics analysis for fabric drying. Apart from these benefits, the proposed drying model can also be applied to other industrial processes where high-temperature air is needed such as drying of timber application since all drying consists of four stages including warming-up, constant drying rate, falling drying rate and blowing.

\section{Acknowledgements}

The work was financially supported by Institute of Nonlinear Sciences of Donghua University (15D110926) and Doctoral Program of Higher Education of China (CUSF-DH-D-2016067).

\section{References}

[1] Ng, A. B.; Deng, S. A New Termination Control Method for a Clothes Drying Process in a Clothes Dryer. Appl. Energy 2008, 85, 818-829.

[2] Stawreberg, L.; Nilsson, L. Potential Energy Savings Made by Using a Specific Control Strategy when Tumble Drying Small Loads. Appl. Energy 2013, 102, 484-491.

[3] Hasanbeigi, A.; Price, L. A Review of Energy Use and Energy Efficiency Technologies for the Textile Industry. Renewable Sustainable Energy Rev. 2012, 16, 3648-3665. 
[4] Akyol, U.; Kahveci, K.; Cihan, A. Determination of Optimum Operating Conditions and Simulation of Drying in a Textile Drying Process. J. Text. Inst. 2013, 104, 170-177.

[5] Yadav, V.; Moon, C. Fabric-Drying Process in Domestic Dryers. Appl. Energy 2008, 85, $143-158$.

[6] Brunner, R. A. Heat Recovery System for Clothes Dryer. Google Patents, 2007.

[7] Deans, J. The Modelling of a Domestic Tumbler Dryer. Appl. Therm. Eng. 2001, 21, 977990.

[8] Braun, J.; Bansal, P.; Groll, E. Energy Efficiency Analysis of Air Cycle Heat Pump Dryers. Int. J. Refrig. 2002, 25, 954-965.

[9] Kudra, T. Energy Aspects in Drying. Drying Technol. 2004, 22, 917-932.

[10] Cay, A.; Tarakçığlu, I.; Hepbasli, A. Exergetic Analysis of Textile Convective Drying with Stenters by Subsystem Models: Part 1-Exergetic Modeling and Evaluation. Drying Technol. 2010, 28, 1359-1367.

[11] Cay, A.; Tarakçığlu, I.; Hepbasli, A. Exergetic Analysis of Textile Convective Drying with Stenters by Subsystem Models: Part 2-Parametric Study on Exergy Analysis. Drying Technol. 2010, 28, 1368-1376.

[12] Van Meel, D. Adiabatic Convection Batch Drying with Recirculation of Air. Chem. Eng. Sci. 1958, 9, 36-44.

[13] Fudholi, A.; Othman, M. Y.; Ruslan, M. H.; Yahya, M.; Zaharim, A.; Sopian, K. The Effects of Drying Air Temperature and Humidity on the Drying Kinetics of Seaweed. 4th WSEAS International Conference on Engineering Mechanics, Structures, Engineering Geology, EMESEG'11, 2nd International Conference on Geography and Geology 2011, WORLD-GEO'11, 5th International Conference on EDEB'112011.

[14] Piccagli, S.; Visioli, A.; Colombo, D. An Efficient Control for a Domestic Tumble Dryer. Emerging Technologies \& Factory Automation, 2009 ETFA 2009 IEEE Conference on, IEEE, 2009. pp. 1-4.

[15] Conde, M. R. Energy Conservation with Tumbler Drying in Laundries. Appl. Therm. Eng. 1997, 17, 1163-1172.

[16] Wu, Y. L.; Chien, K. H.; Yang, K. S.; Lo, C. C. A Study on the Impact of Different Tumbler Inlet Conditions on the Clothes Dryer's Tumbler Efficiency. Adv. Mater. Res. Trans Tech Publ. 2011, 339, 188-192.

[17] Ameen, A.; Bari, S. Investigation into the Effectiveness of Heat Pump Assisted Clothes Dryer for Humid Tropics. Energy Convers. Manage. 2004, 45, 1397-1405.

[18] Krokida, M.; Bisharat, G. Heat Recovery from Dryer Exhaust Air. Drying Technol. 2004, 22, 1661-1674.

[19] El-Sebaii, A.; Aboul-Enein, S.; Ramadan, M.; El-Gohary, H. Experimental investigation of an indirect type natural convection solar dryer. Energy Convers. Manage. 2002, 43, $2251-2266$. 
[20] Crow, R. M.; Slater, K. The Automatic Control of the Drying of Textile Fabrics. Text. Res. J. 1974, 44, 309-313.

[21] Higgins, L.; Anand, S.; Hall, M.; Holmes, D. Effect of Tumble-drying on Selected Properties of Knitted and Woven Cotton Fabrics: Part I: Experimental Overview and the Relationship between Temperature Setting, Time in the Dryer and Moisture Content. $J$. Text. Inst. 2003, 94, 119-128.

[22] Zhu, G.; Kremenakova, D.; Wang, Y.; Militky, J. Temperature changes of plain cotton fabric during liquid absorption process. Int. J. Clothing Sci. Technol. 2015, 27, 600-606.

[23] Wang, L.; Liu, J.; Pan, R.; Gao, W. Inspecting Anisotropy in Wrinkle Recovery Angle of Woven Fabric. J. Text. Inst. 2015, 107, 711-718.

[24] Buisson, Y.; Rajasekaran, K.; French, A.; Conrad, D.; Roy, P. Qualitative and Quantitative Evaluation of Cotton Fabric Damage by Tumble Drying. Text. Res. J. 2000, 70, 739-743.

[25] Salin, J.-G. Mass Transfer from Wooden Surfaces and Internal Moisture Non-Equilibrium. Drying Technol. 1996, 14, 2213-2224.

[26] Tsang, K.; Vesilind, P. Moisture Distribution in Sludges. Water Sci. Technol. 1990, 22, 135142.

[27] Nam, S.; French, A. D.; Condon, B. D.; Concha, M. Segal Crystallinity Index Revisited by the Simulation of X-ray Diffraction Patterns of Cotton Cellulose I $\beta$ and Cellulose II. Carbohydr. Polym. 2016, 135, 1-9.

[28] Leon, M. A., Kumar, S. Design and Performance Evaluation of a Solar-Assisted Biomass Drying System with Thermal Storage. Drying Technol. 2008, 26, 936-947.

[29] Trelea, I.-C.; Courtois, F.; Trystram, G. Dynamics Analysis and Control Strategy for a Mixed Flow Corn Dryer. J. Process Control 1997, 7, 57-64.

[30] Ogonowski, Z. Drying Control System for Spray Booth with Optimization of Fuel Consumption. Appl. Energy 2011, 88, 1586-1595.

[31] Hearle, J. A. Fringed Fibril Theory of Structure in Crystalline Polymers. J. Polymer Science 1958, 28, 432-435.

[32] Široká, B., Manian, A. P.; Noisternig, M. F.; Henniges, U., Kostic, M.; Potthast, A.; Griesser, U. J.; Bechtold, T. Wash-dry Cycle Induced Changes in Low-ordered Parts of Regenerated Cellulosic Fibers. J. Appl. Polym. Sci. 2012, 126, E397-E408.

[33] Wei, Y.; Hua, J.; Ding, X. A Mathematical Model for Simulating Heat and Moisture Transfer Within Porous Cotton Fabric Drying inside the Domestic Air-Vented Drum Dryer. J. Text. Inst. 2016, 108, 1074-1084.

[34] Higgins, L.; Anand, S.; Hall, M.; Holmes, D. Effect of Tumble-Drying on Selected Properties of Knitted and Woven Cotton Fabrics: Part II: Effect of Moisture Content, Temperature Setting, and Time in Dryer on Cotton Fabrics. J. Text. Inst. 2003, 94, 129139. 
[35] Liljemark, N. T.; Åsnes, H.; Kärrholm, M. The Sensitivity of Cotton Fabrics to Wrinkling During Changing Moisture Regain and its Dependence on Setting and Cross-Linking Parameters. Text. Res. J. 1971, 41, 526-533.

[36] Yao, M.; Zhou, J.; Huang, S.; Shao, L.; An, R.; Fan, D. Textile Materials Science; Textile Industry Press: Beijing, 1993.

[37] AATCC Test Method 124. Appearance of Fabrics after Repeated Home Laundering. AATCC Technical Manual. 2014, 210-213. 
Table 1. Fabric specifications

\begin{tabular}{|c|c|c|c|c|c|c|}
\hline Test & Fabric & Fabric & Thickness & Relative & Load $(\mathrm{g})$ & Specific heat \\
sample & design & weight & $(\mathrm{mm})$ & porosity & & capacity* $(\mathrm{kJ} / \mathrm{kg} . \mathrm{K})$ \\
content & & $(\mathrm{g} / \mathrm{m} 2)$ & & $(\%)$ & & \\
\hline $100 \%$ & Plain & $145( \pm 0.03)$ & $0.79( \pm 0.03)$ & 76.7 & $5000( \pm 10)$ & $1.224 .00( \pm 0.14)$ \\
cotton & & & & & & \\
\hline
\end{tabular}

*Specific heat capacity of cotton is $1.224 .0(\mathrm{kj} / \mathrm{kg} . \mathrm{K}){ }^{[36]}$ 
Table 2. Humidity of exhaust air for drying stage determination

\begin{tabular}{|c|c|c|c|c|}
\hline \multirow{2}{*}{ Humidity of } & \multicolumn{4}{|c|}{ Temperature and relative humidity sensor (T/RH2) at the exit of the exhaust } \\
Exhaust air (\%) & \multicolumn{4}{|c|}{ duct } \\
\cline { 2 - 5 } & End of Stage 1 & End of Stage 2 & End of Stage 3 & Stage 4 \\
\hline Staged drying & $100 \%$ & $95 \%$ & $42 \%$ & $38 \%$ \\
\hline
\end{tabular}


Table 3. Drying parameters

\begin{tabular}{|c|c|c|c|c|c|c|c|c|c|c|c|c|}
\hline \multirow{3}{*}{$\begin{array}{c}\text { Test } \\
\text { number }\end{array}$} & \multicolumn{12}{|c|}{ Drying conditions - parameters of each period } \\
\hline & \multicolumn{4}{|c|}{ Heater power $(\mathrm{W})$} & \multicolumn{4}{|c|}{ Air flow velocity } & \multicolumn{4}{|c|}{ Rotating speed of drying drum } \\
\hline & $\mathrm{S} 1$ & $\mathrm{~S} 2$ & $\mathrm{~S} 3$ & $\mathrm{~S} 4$ & $\mathrm{~S} 1$ & $\mathrm{~S} 2$ & S3 & $\mathrm{S} 4$ & S1 & S2 & S3 & $\mathrm{S} 4$ \\
\hline \multirow[t]{2}{*}{1} & 400 & 400 & 400 & 400 & 6.8 & 6.8 & 6.8 & 6.8 & $45-50$ & $45-50$ & $45-50$ & $45-50$ \\
\hline & 0 & 0 & 0 & 0 & & & & & & & & \\
\hline \multirow[t]{2}{*}{2} & 400 & 400 & 300 & 150 & 6.8 & 8.5 & 8.5 & 6.8 & $50-55$ & $45-50$ & $40-45$ & $45-50$ \\
\hline & 0 & 0 & 0 & 0 & & & & & & & & \\
\hline \multirow[t]{2}{*}{3} & 400 & 400 & 300 & 400 & 8.5 & 8.5 & 8.5 & 8.5 & $50-55$ & $40-45$ & $40-45$ & $45-45$ \\
\hline & 0 & 0 & 0 & 0 & & & & & & & & \\
\hline 4 & 150 & 400 & 400 & 150 & 8.5 & 6.8 & 8.5 & 8.5 & $40-45$ & $40-45$ & $50-55$ & $40-45$ \\
\hline \multirow[t]{3}{*}{5} & 150 & 400 & 150 & 400 & 8.5 & 8.5 & 6.8 & 6.8 & $50-55$ & $40-45$ & $50-55$ & $50-55$ \\
\hline & 150 & 400 & 150 & 150 & 6.8 & 6.8 & 6.8 & 8.5 & $50-55$ & $50-55$ & $40-45$ & $40-45$ \\
\hline & 0 & 0 & 0 & 0 & & & & & & & & \\
\hline \multirow[t]{2}{*}{7} & 400 & 400 & 400 & 150 & 6.8 & 8.5 & 6.8 & 6.8 & $50-55$ & $50-55$ & $50-55$ & $40-45$ \\
\hline & 0 & 0 & 0 & 0 & & & & & & & & \\
\hline
\end{tabular}




\begin{tabular}{|c|c|c|c|c|c|c|c|c|c|c|c|c|}
\hline 8 & 400 & 150 & 150 & 400 & 8.5 & 8.5 & 8.5 & 8.5 & $50-55$ & $45-50$ & $50-55$ & $40-45$ \\
\hline 9 & 150 & 150 & 400 & 400 & 8.5 & 6.8 & 6.8 & 6.8 & $40-45$ & $50-55$ & $40-45$ & $40-45$ \\
\hline 10 & 0 & 0 & 0 & 0 & & & & & & & & \\
\hline 11 & 40 & 400 & 400 & 400 & 6.8 & 8.5 & 8.5 & 8.5 & $40-45$ & $50-55$ & $40-45$ & $50-55$ \\
\hline 12 & 400 & 150 & 400 & 150 & 8.5 & 6.8 & 6.8 & 8.5 & $50-55$ & $40-45$ & $45-50$ & $50-55$ \\
\hline & 0 & 0 & 0 & 0 & & & & & & & & \\
\hline
\end{tabular}

1 is the single process drying model; $2-12$ are the staged drying model. 
Table 4. Testing results of above different procedures

\begin{tabular}{|c|c|c|c|c|}
\hline Test number & $\begin{array}{c}\text { Energy } \\
\text { consumption } \\
(\mathrm{KW} \cdot \mathrm{h})\end{array}$ & $\begin{array}{l}\text { Drying time } \\
\text { (min) }\end{array}$ & $\begin{array}{c}\text { Final moisture } \\
\text { content of fabric (\%) }\end{array}$ & $\begin{array}{c}\text { Fabric } \\
\text { smoothness }\end{array}$ \\
\hline 1 & 4.82 & 55 & -2.17 & .2 \\
\hline 2 & 3.78 & 60 & 1.78 & 2.1 \\
\hline 3 & 4.42 & 55 & -2.75 & 1.3 \\
\hline 4 & 4.32 & 75 & 2.98 & 2.4 \\
\hline 5 & 4.62 & 85 & -1.76 & 1.6 \\
\hline 6 & 4.89 & 120 & 4.78 & 2.5 \\
\hline 7 & 3.98 & 50 & 0.98 & 1.7 \\
\hline 8 & 4.65 & 110 & 2.87 & 1.9 \\
\hline 9 & 4.22 & 105 & 1.12 & 1.6 \\
\hline 10 & 3.87 & 65 & 0.98 & 1.2 \\
\hline 11 & 4.36 & 100 & 2.13 & 2.1 \\
\hline 12 & 4.06 & 95 & 2.96 & 2.4 \\
\hline
\end{tabular}


Figure1. Theoretical analysis of the fabric drying process (a) The changes of the moisture content of fabric and humidity of exhaust air during the drying process, (b) The changes of the fabric temperature and drying air temperature during the drying process.

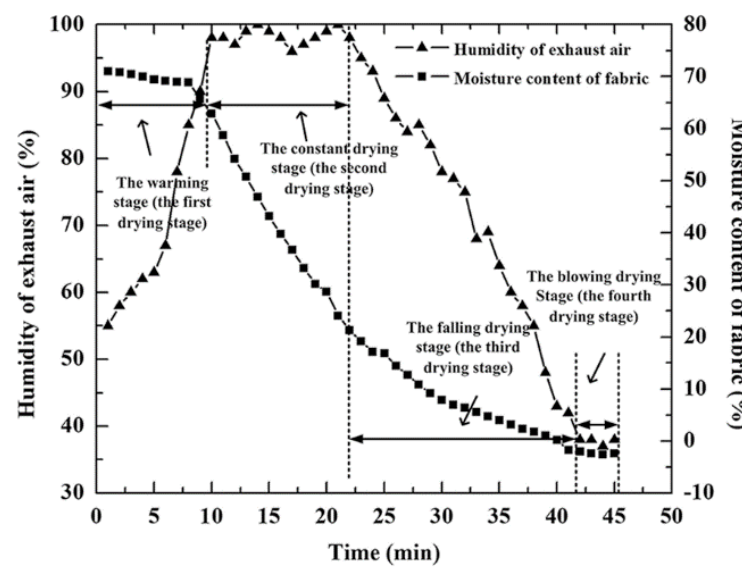

(a)

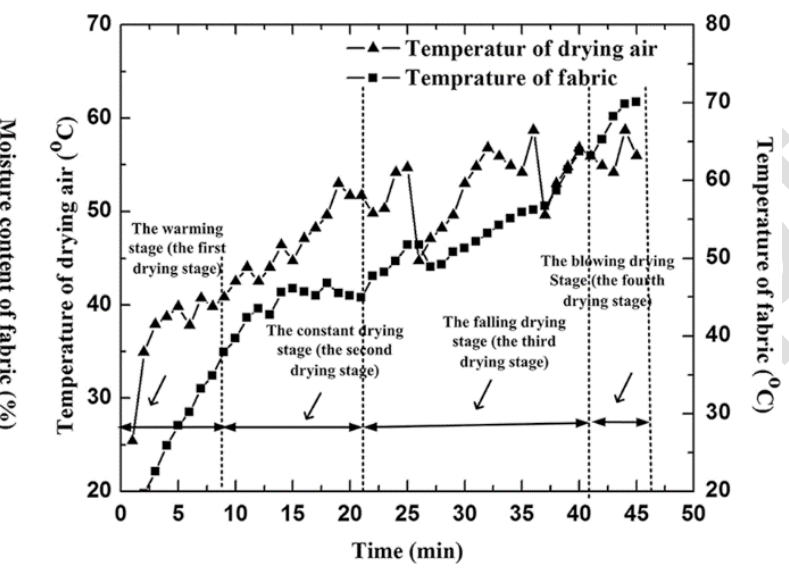

(b) 
Figure 2. Mechanism of moisture migration in drying process.

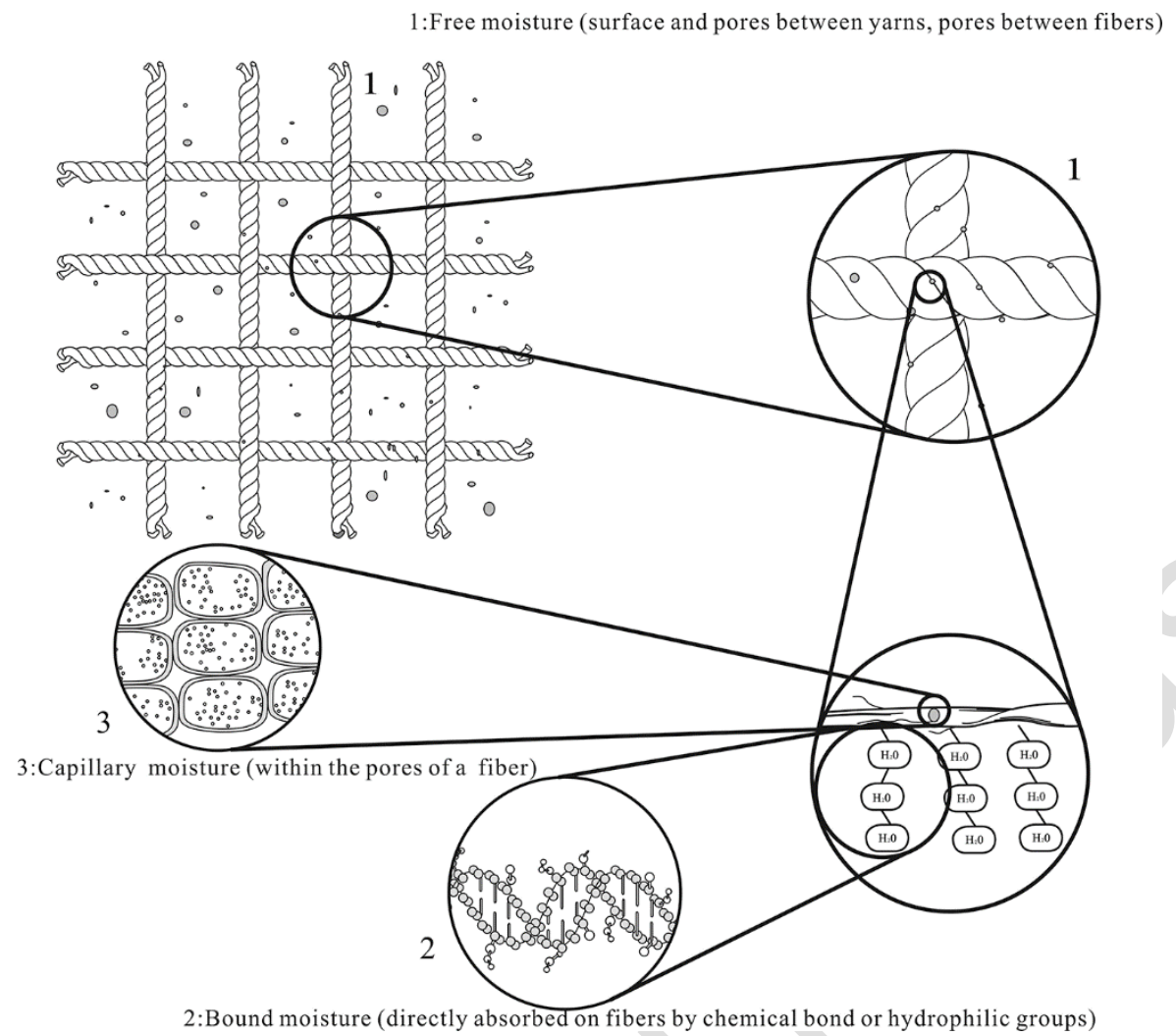


Figure 3. Configuration and design of the prototype platform.

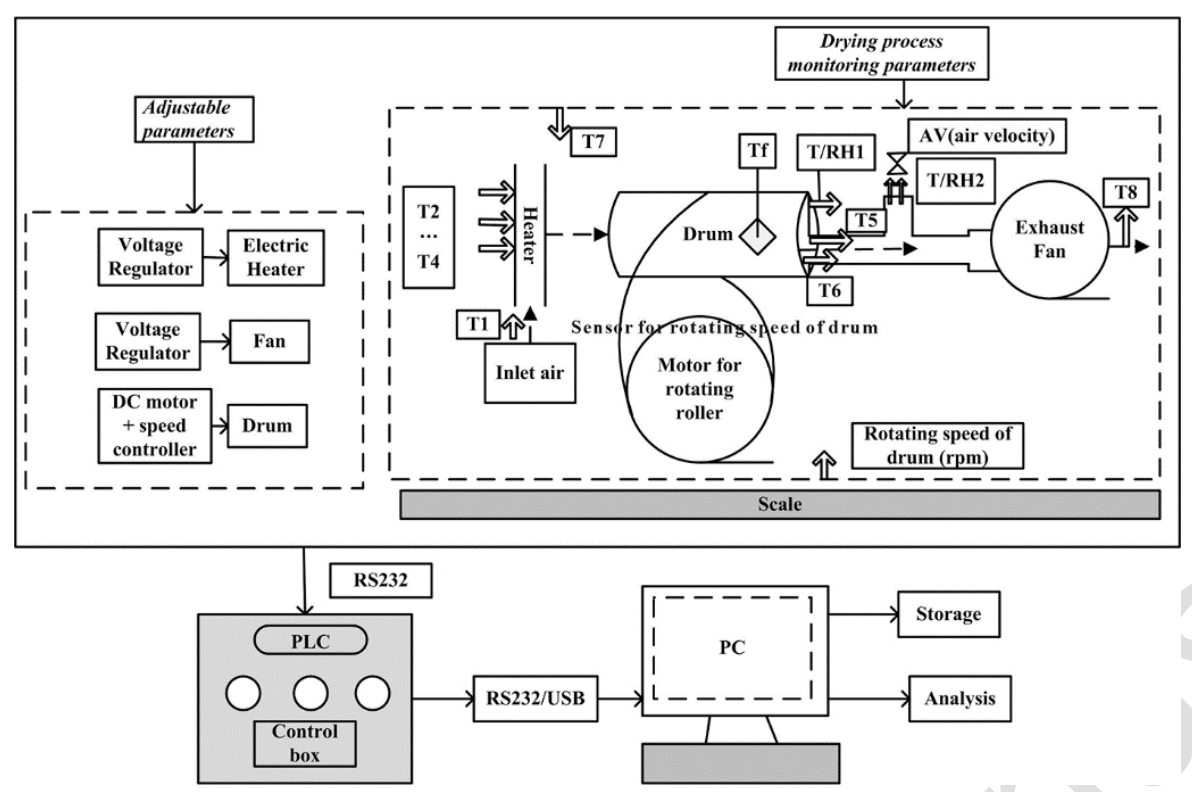


Figure 4. The main parts of the prototype platform.

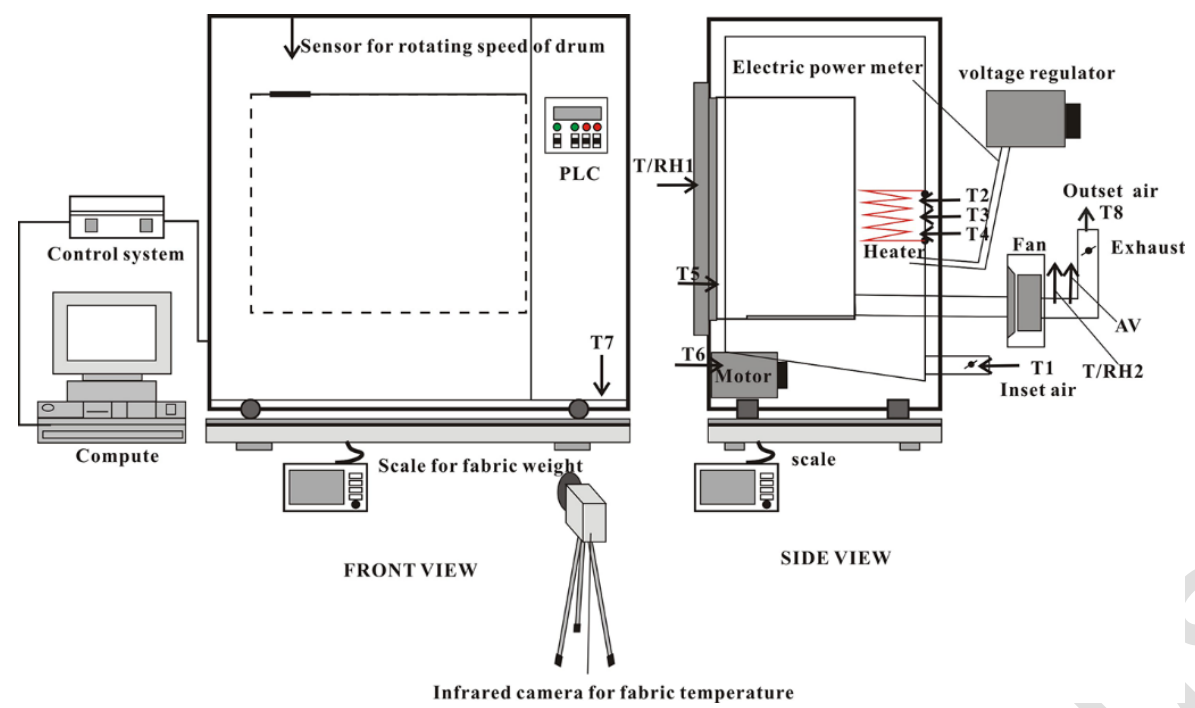


Figure 5. Heat and mass transfer process in drying chamber.

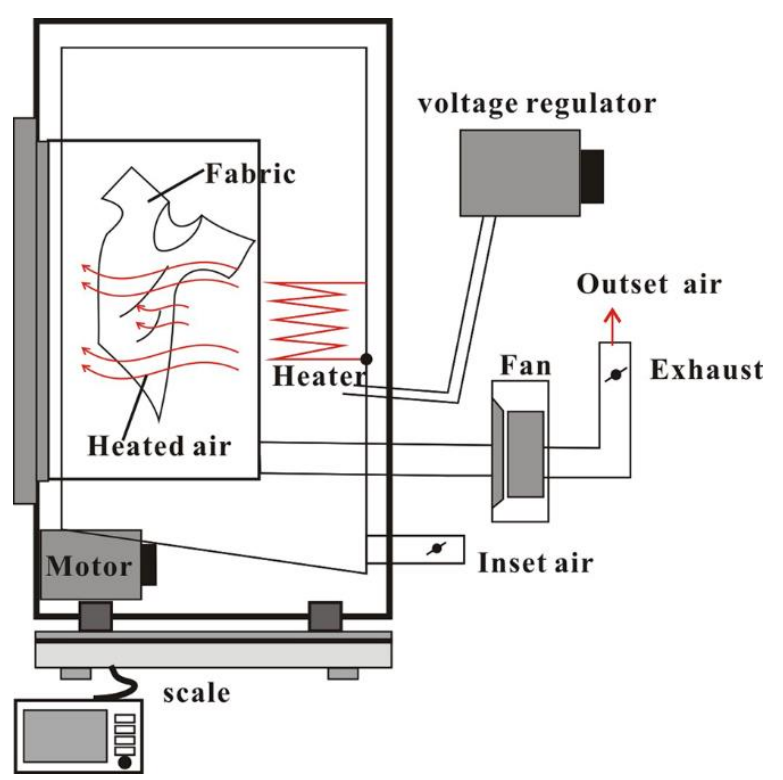


Figure 6. Adaptive control strategy for the prototype platform.

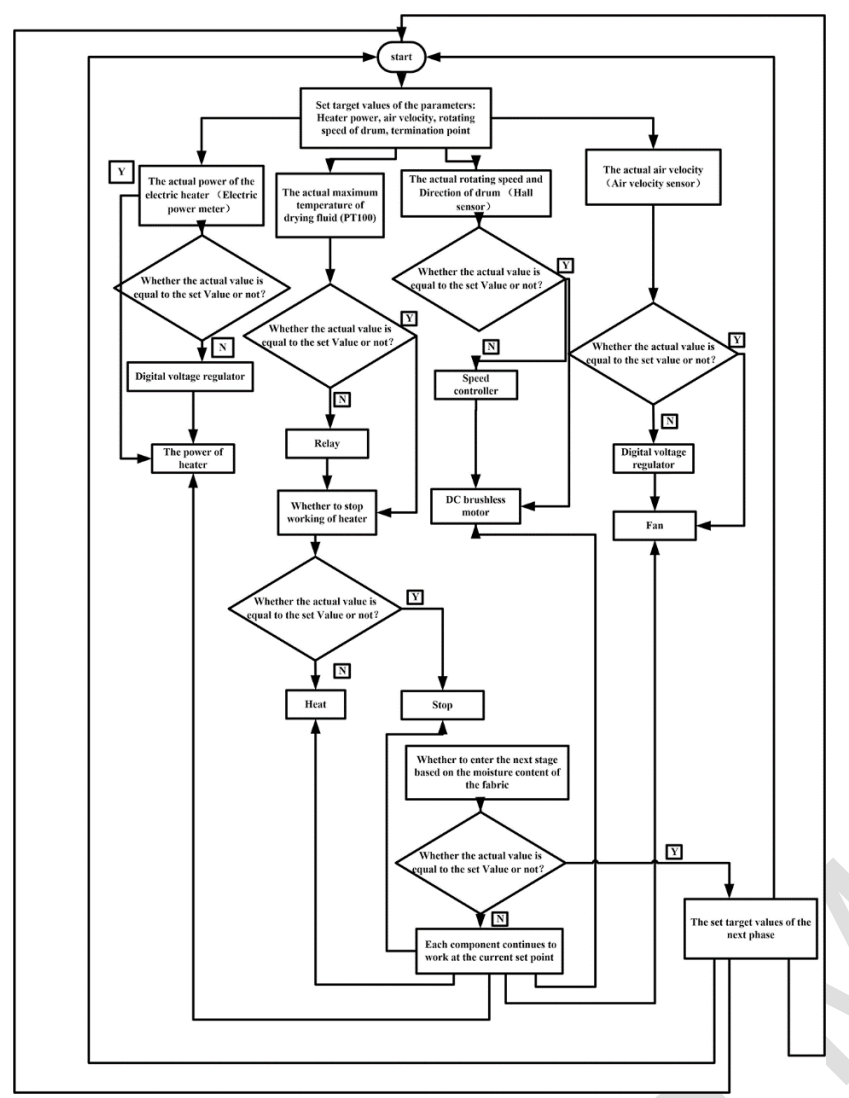


Figure 7. GUI of the program.

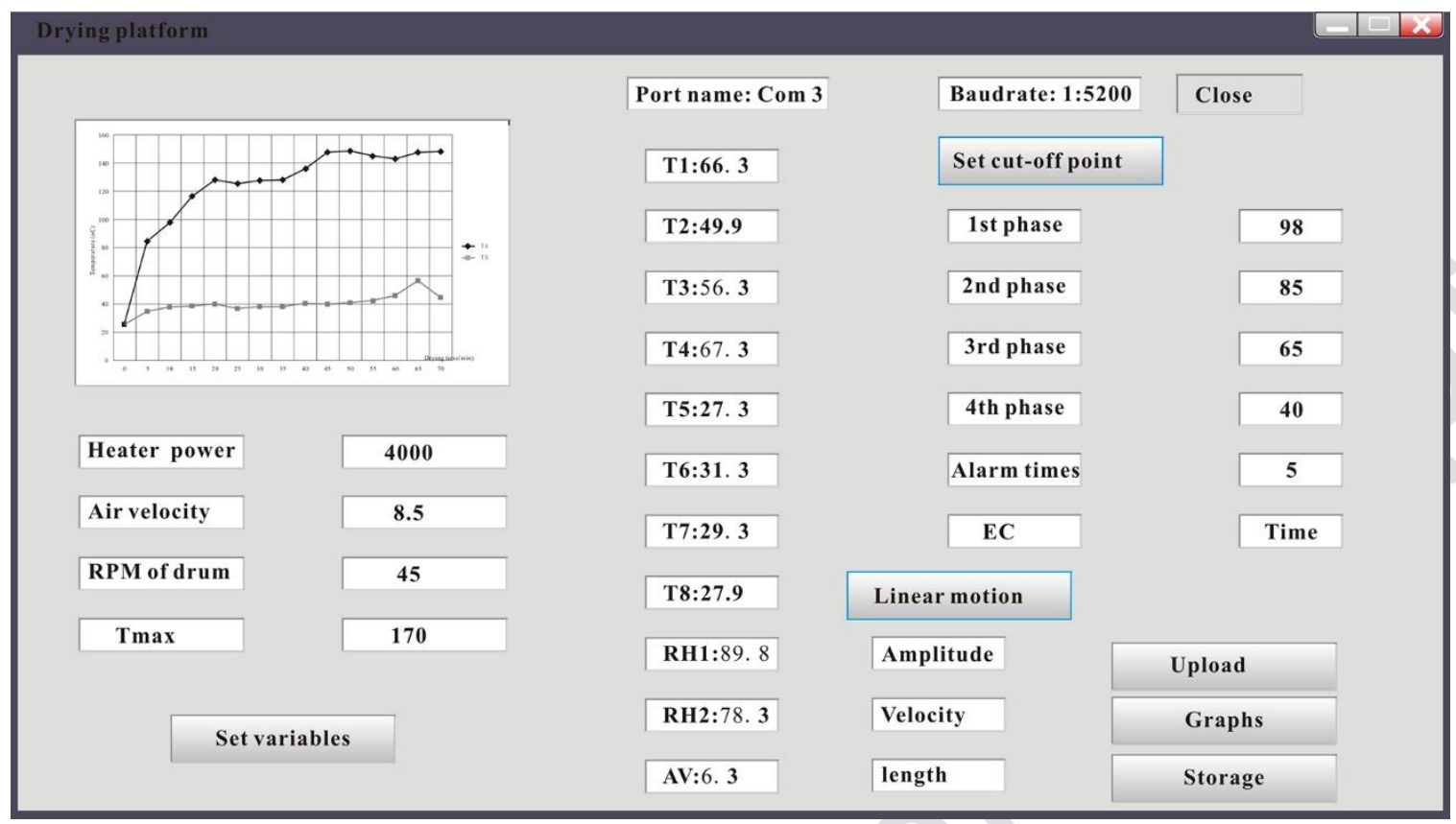


Figure 8. Realization of the prototype platform.

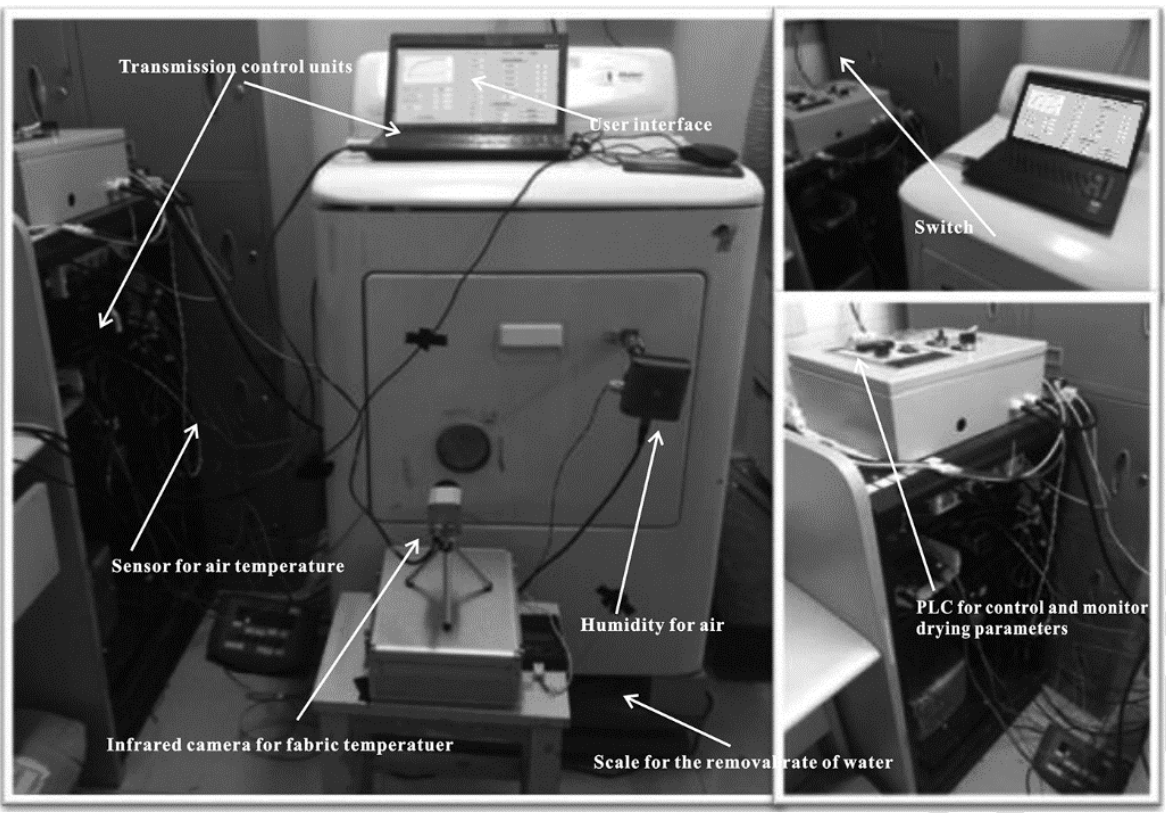


Figure 9. Fabric smoothness (a) Single fixed drying model, (b) Staged drying model.
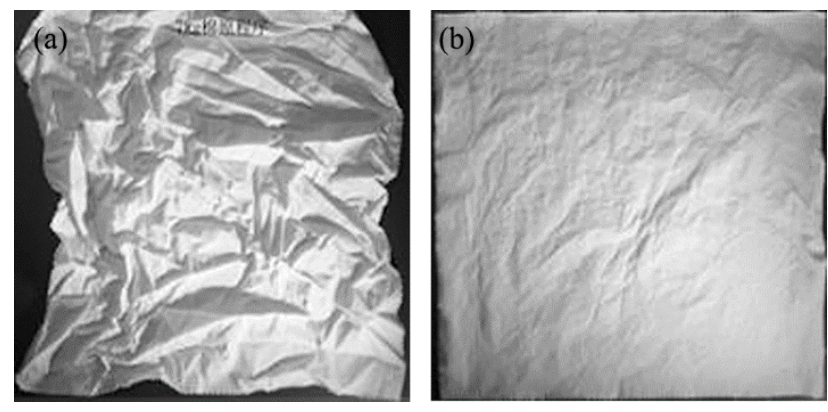